\title{
Determination of the shelf life of a functional beverage by accelerated testing
}

\author{
Arthur Khasanov ${ }^{1 *}$, Natalia Matveeva ${ }^{1}$ \\ ${ }^{1}$ St. Petersburg National Research University of Information Technologies, Mechanics and Optics, \\ Lomonosov St., 9, St. Petersburg, 191002, Russia
}

\begin{abstract}
In the course of research, the shelf life of a functional beverage based on plant raw materials was determined. To determine the shelf life the method of accelerated shelf life testing based on the Arrhenius model was used. As a controlled indicator, the concentration of anthocyanins is selected, which determine the functionality of this beverage. The test was carried out at a temperature of 50 degrees Celsius. The control sample was stored at a temperature of 20 degrees Celsius. Fixing the value of anthocyanins was performed every 3-4 days. As a result, the critical value was the value of anthocyanins on day 14 . It fell by $55 \%$ from the original value. Thus, according to the calculations and the law of Arrhenius, the shelf life of the drink was 3.7 months.
\end{abstract}

\section{Introduction}

The food industry needs to expand the range of new functional beverages, and therefore, to obtain information about their shelf life. Shelf life can be considered as a period of time during which a food product is stored and sold without significant loss of quality or functional properties [1]. In this sense, the expiration of the expiration date does not mean biological spoilage of the product - it just does not meet the standard quality indicators. In another sense, the expiration date is the expiration date of the product, after which the product is not suitable for human consumption. Thus, the shelf life of food is one of the most important indicators characterizing the quality or loss of product quality. Before recommending a new product to the consumer market, manufacturers need to set an expiration date for the purpose of safety.

To ensure quality and stability during the expiration date, it is necessary to timely identify, manage and control risk factors associated with quality: temperature fluctuations, mechanical influences, chemical changes, light exposure, microbiological damage, organoleptic properties (appearance, aroma, taste). To this end, tests are carried out that determine or confirm an acceptable "life" of the product for a short period of time, taking into account the technology, actual storage conditions and sales to the consumer [2]. Deterioration in the quality of a food product can be expressed by a quantitative change in one or more indicators, for example, by the nutrient content or by a change in organoleptic indicators (extraneous taste, colour loss, change in taste). For long-term storage of the

*Corresponding author: email@yandex.ru 
product, an express assessment of the expected shelf life is required. In this case, they resort to the method of accelerated shelf life testing - ASLT (Accelerated Shelf Life Testing), shortening the process of obtaining the necessary experimental data $[2,3]$. The ASLT method is applicable to any process of quality loss or food spoilage for which an adequate kinetic model is known. There are several principles of ASLT, but they all come down to three points:

- obtaining reliable data on the damage process in a short period of time;

- selection of the model used;

- a method for predicting the actual shelf life of a product.

The kinetic model must necessarily include temperature, which significantly affects the rate of a chemical reaction. In addtion, it is necessary to decide how many factors should be used for the test (one or more). The simplest and most widely used ASLT method is based on the application of a single acceleration factor. To obtain an accurate forecast of the shelf life, the validity (validity) of the kinetic model used is crucial. Unfortunately, the validity of the model cannot be fully confirmed within the ASLT, since the test conditions do not correspond to the actual storage conditions. Preliminary information can be obtained on the basis of available empirical data or repeatedly carried out physical and chemical theoretical positions [3, 4]. Such a reasonable model is the Arrhenius model, which relates the rate of a chemical reaction with temperature changes and is described by the Arrhenius equation:

$$
K=K_{0} \times \exp ^{-\frac{E_{a}}{R \times T}}
$$

$\mathrm{K}_{0}$ is a constant;

$E_{a}$ is activation energy;

$\mathrm{R}$ is the gas constant;

$\mathrm{T}$ is the absolute temperature.

There is an extensive database of activation energy values for various chemical spoilage reactions of food products that can be used to obtain a reasonable estimate of the effect of temperature on the reaction rate. It is possible to simplify the model (exclude the $\mathrm{K}_{0}$ estimate) by using the ratio between reaction rates when the temperature changes by an arbitrary value (usually the temperature step is changed by $10^{\circ} \mathrm{C}$ ) [5]. This ratio of speeds is known as criterion $\mathrm{Q}_{10}$ and shows how much faster the reaction proceeds with increasing temperature for every $10^{\circ} \mathrm{C}$.

$$
Q_{10}=\frac{K_{t}+10}{K \times T}
$$

This information is used to predict the expected shelf life of the product [6]. For example: with a standard temperature increase of $10^{\circ} \mathrm{C}$, the chemical reaction rate in beverage doubles. For the standard temperature, it is customary to take the air temperature in the storehouse as $20^{\circ} \mathrm{C}$ [7]. If at a temperature of $30^{\circ} \mathrm{C}$ the indicator $\mathrm{Q}_{10}=2$ and the product is stable for ten weeks at this temperature, then at $20^{\circ} \mathrm{C}$ the stability will be: $2 \cdot 10$ weeks $=20$ weeks $[3,8]$. The ease of use of the $\mathrm{Q}_{10}$ criterion allows you to quickly get the necessary results with minimal practical effort. Based on the considered theoretical prerequisites, the aim of the work is to determine the shelf life by the accelerated testing method (ASLT) of the developed functional beverage based on tea and fruit and berry juices using the Arrhenius model and criterion $\mathrm{Q}_{10}$. The minor ingredients of the formulation were selected dry extracts of their fruit and berry raw materials. A functional beverage has adaptogenic action $[9,10]$. 


\section{Objects and research methods}

A temperature of $50^{\circ} \mathrm{C}$ was selected for testing the samples. Samples from one batch of the beverage were kept at a temperature of $50^{\circ} \mathrm{C}$ in parallel measurements in a thermostat, and a control sample was tested at a standard temperature of $20^{\circ} \mathrm{C}$. The duration of the test was determined by the time from the beginning of the experiment to the moment when the beverage is deemed unsuitable for one or more controlled indicators. Beverage samples were taken at time intervals equal to $0 ; 3 ; 7 ; 10 ; 14 ; 17 ; 21 ; 24$ days and using analytical methods, we determined the main physicochemical quality indicators: the mass fraction of anthocyanins and organoleptic quality indicators (colour, smell, taste) by tasting method and also additional indicators : solids content, active acidity $(\mathrm{pH})$, total (titratable) acidity $[7,11]$.

The finished beverage, which consists of the following components: direct-squeezed juices from red grapes, carrots, kiwi, blueberries, apples, black and green tea, plant extracts of Centella asiatica and Hoodia gordonii was poured into three sterile containers of $120 \mathrm{ml}$ : two - parallel samples, the third is a control sample, kept at a temperature of $20^{\circ} \mathrm{C}$ throughout the study, and parallel were tested in an thermostat at a temperature of $50^{\circ} \mathrm{C}$ [12].

In the framework of the study, physicochemical parameters were determined that were controlled during the experiment: the content of anthocyanins was determined spectrophotometrically in accordance with the technochemical control of fruit and berry raw materials using a PE-5300VI spectrophotometer; active acidity $(\mathrm{pH})$ on a Titrino plus $\mathrm{pH}$ meter [13]. Solids content - by refractometric method on a PTR 46 refractometer; total (titratable) acidity was determined by titration with $0.1 \mathrm{~N} \mathrm{NaOH}$ solution. Table 1 .

Table 1. Physico-chemical and organoleptic characteristics of the beverage at a temperature of $20^{\circ} \mathrm{C}$

\begin{tabular}{|c|c|}
\hline Level of quality & Value \\
\hline The content of anthocyanins, $\mathrm{mg} / \mathrm{l}$ & 552.2 \\
\hline $\mathrm{pH}$ & 3.5 \\
\hline Solids content, $\%$ & 8.1 \\
\hline Titratable acidity, $\mathrm{g} / \mathrm{l},{ }^{\circ}$ & $0.62 / 6.2$ \\
\hline Colour & saturated ruby burgundy \\
\hline Smell & $\begin{array}{c}\text { corresponds to the raw } \\
\text { materials used }\end{array}$ \\
\hline Taste & sweet and sour \\
\hline
\end{tabular}

\section{Results and discussions}

Figure 1 shows the results of testing the beverage by accelerated aging to predict its shelf life. As noted earlier, the change in the mass fraction of anthocyanins, as well as organoleptic indicators (appearance, colour, taste, smell) were taken as controlled indicators. 


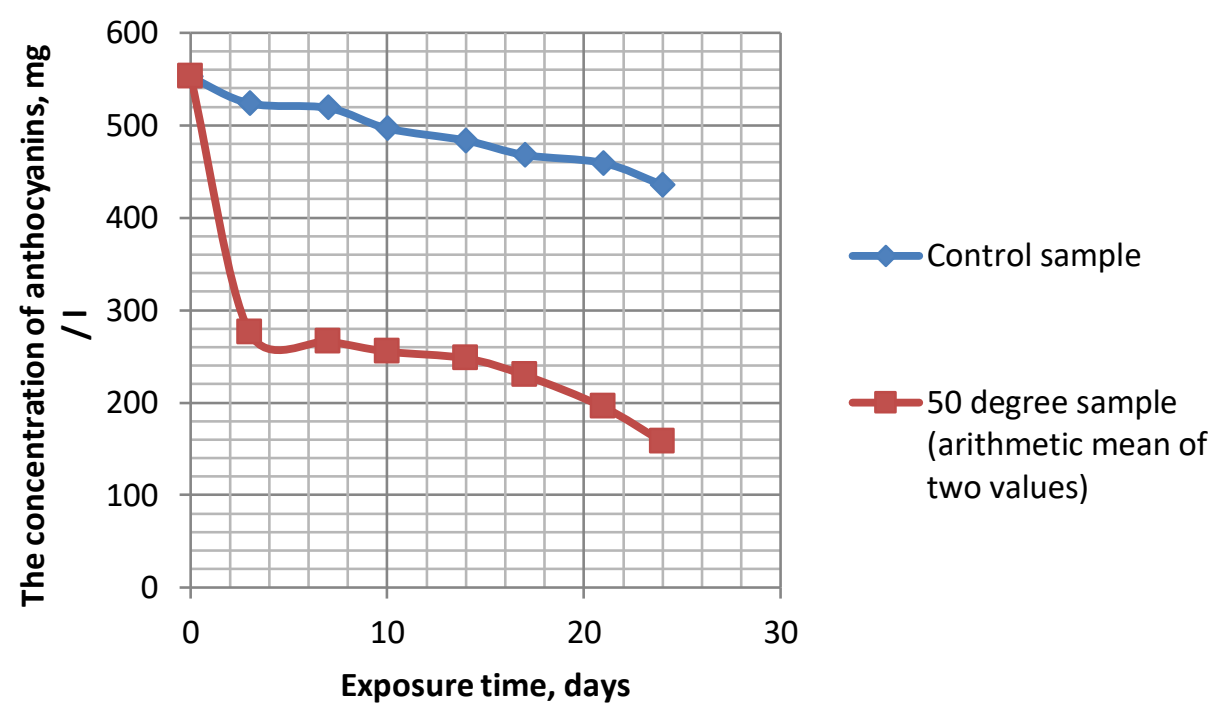

Fig. 1. Change in anthocyanins concentration

An analysis of the curves of changes in anthocyanins during the aging of the beverage at a temperature of $50{ }^{\circ} \mathrm{C}$ shows that a sharp decrease in the concentration of anthocyanins by $50 \%$ occurred after 3 days. Then, from day 3 to day 14 , anthocyanins slightly decreased by $5 \%$. From 14 to 24 , they decreased to the minimum value and practically collapsed by $72 \%$ of the initial measurement. In the control sample, there was a slow, systematic change in concentration over 24 days by $22 \%$ without changing organoleptic indicators. The results showed that anthocyanins have low resistance to elevated temperatures with prolonged exposure. The colour of the beverage acquired a brown hue, which confirms the decomposition of anthocyanins [14].

Thus, according to the results of the degradation of anthocyanins, the critical point is taken to be the value that corresponds to 14 days, due to the fact that the degradation was more than $50 \%$, which is a significant loss of functional properties. Thus, the shelf life of a beverage can be determined based on a largely controlled quality criterion: $14 \cdot 2 \cdot 2 \cdot 2 / 30$ $=112$ days or 3.7 months. Loss of anthocyanins by this time was $55 \%$.

Storage of the beverage at a standard temperature of $20^{\circ} \mathrm{C}$ (control sample) showed that the main indicators - the mass fraction of anthocyanins changed slightly. The organoleptic characteristics — appearance, colour, and taste — remained almost unchanged: the beverage remained bright red in colour, and sweet and sour in taste, inherent in the taste of the original beverage $[15,16]$.

\section{Acknowledgement}

The work is carried out on the subject IS UB RAS № ГР AAAA-A17-117012610022-5.

\section{References}

1. P. Paken Functional and special purpose beverages. (St. Petersburg, Professiya Publ., 2010) 
2. D. Kilkast, P. Subramaniam The stability and shelf life. Soft drinks juices, beer and wine. (St. Petersburg, Professiya Publ., 2012)

3. S.G. Gafizov. Engineering - From Theory to Practice. 43, 59-72 (2015).

4. R. Stele The shelf life of food products. Calculation and testing. (St. Petersburg, Professiya Publ., 2006)

5. M.N. Shkol'nikova, E.V. Aver'yanova, I.V. Shcheglova, Technique and technology of food production. 1, 52-56 (2009).

6. V.V. Okrepilov, A.V. Chernikova, A.A. Peshekhonov, I.V. Rudakova. Measurement Techniques. 61. 11. P. 1074-1080. (2019) DOI: 10.1007/s11018-019-01551-y

7. S.A. Aleksandrovskii. Bulletin of Kazan Technological University.24 (17), 178-181 (2014). DOI: 10.24263/2225-2924-2018-24-5-21

8. K. Valentas, E. Rotshtein, R.P. Singkh, Food Engineering. Directory (St. Petersburg, Professiya Publ., 2004)

9. L.A. Dogaeva, N.T. Pekhtereva Beer and beverages. 5, 62-65 (2011). DOI: 10.20914/2310-1202-2016-1-221-226

10. Kh.K. Gadeleva, R.V. Kunakova, E.V. Aver'yanova, Functional Foods. (Moscow, Knorus Publ., 2012)

11. E.A. Sosyura Development of technology of beverages of a functional purpose on the basis of grape juice. Candidate' s thesis. Krasnodar, (2014) DOI 10.30679/2587-98472019-23-220-224

12. R. Sharma. The Australian journal of dairy technology. 60(2), 196-199 (2006). DOI: 10.1007/s11947-011-0683-7

13. B.M. MacKenna The structure and texture of foods. Natural emulsion products. (St. Petersburg, Professiya Publ., 2008)

14. V.A. Markosov, N.M. Ageeva, R.V. Gabliya. Winemaking and Viticulture. 4, 24-25. (2007) DOI: 10.17586/2310-1164-2016-9-4-75-82

15. D. Kilcast Combining instrumental and sensory methods in food quality control. Sensor analysis for food and beverage quality control. (Cambridge: Woodhead publishing, 2010). DOI: 10.1533/9781845699512.2.97

16. N.A. Matveeva, A.R. Khasanov. Scientific journal Processes and Food Production Equipment, 4 (30), 75-82 (2016). DOI: 10.17586/2310-1164-2016-9-4-75-82 